\title{
Role of Lactic Acid Bacteria-Myeloperoxidase Synergy in Establishing and Maintaining the Normal Flora in Man
}

\author{
Robert C. Allen ${ }^{1}$, Jackson T. Stephens Jr. ${ }^{2}$ \\ ${ }^{1}$ Department of Pathology, School of Medicine, Creighton University, Omaha, USA; ${ }^{2}$ ExOxEmis, Inc., Little Rock, USA. \\ Email: RobertAllen@creighton.edu \\ Received July $26^{\text {th }}, 2013$; revised August $26^{\text {th }}, 2013$; accepted September $3^{\text {rd }}, 2013$ \\ Copyright (C) 2013 Robert C. Allen, Jackson T. Stephens Jr. This is an open access article distributed under the Creative Commons \\ Attribution License, which permits unrestricted use, distribution, and reproduction in any medium, provided the original work is \\ properly cited.
}

\begin{abstract}
Lactic acid bacteria (LAB) are incapable of cytochrome synthesis and lack the heme electron transport mechanisms required for efficient oxygen-based metabolism. Consequently, LAB redox activity is flavoenzyme-based and metabolism is fermentative, producing lactic acid, and in many cases, hydrogen peroxide $\left(\mathrm{H}_{2} \mathrm{O}_{2}\right)$. Despite this seeming metabolic limitation, LAB dominate in the normal flora of the mouth, vagina and lower gastrointestinal tract in man. Myeloperoxidase (MPO) is produced by the neutrophil leukocytes and monocytes that provide the innate phagocyte defense against infecting pathogens. MPO is unique in its ability to catalyze the $\mathrm{H}_{2} \mathrm{O}_{2}$-dependent oxidation of chloride $\left(\mathrm{Cl}^{-}\right)$to hypochlorite $\left(\mathrm{OCl}^{-}\right)$. In turn, this $\mathrm{OCl}^{-}$directly reacts with a second $\mathrm{H}_{2} \mathrm{O}_{2}$ to produce singlet molecular oxygen $\left({ }^{1} \mathrm{O}_{2}^{*}\right)$, a metastable electronic excitation state of oxygen with a microsecond lifetime that restricts its combustive reactivity within a submicron radius of its point of generation. Each day a healthy human adult produces about a hundred billion neutrophils containing about 4 femtograms MPO per neutrophil. Inflammatory states and G-CSF treatment increase both neutrophil production and the quantity of MPO per neutrophil. After a short circulating lifetime, neutrophils leave the blood and migrate into body spaces including the mouth, vagina, urinary tract, and gastrointestinal tract. Greater than a hundred thousand neutrophils are lavaged from the mouths of healthy humans; the quantity lavaged is proportional to the blood neutrophil count. MPO selectively and avidly binds to most Gram-positive and all Gram-negative bacteria tested, but LAB do not show significant MPO binding. Neutrophils migrating to normal flora sites release MPO into the LAB-conditioned milieu containing adequate acidity and $\mathrm{H}_{2} \mathrm{O}_{2}$ to support extra-phagocyte MPO microbicidal action. In combination, LAB plus MPO exert a potent synergistic microbicidal action against high MPO-binding microbes. This LAB-MPO synergy provides a mechanism for the establishment and maintenance of LAB in the normal flora of man.
\end{abstract}

Keywords: Myeloperoxidase; Lactic Acid Bacteria; Hydrogen Peroxide; Hypochlorite; Singlet Oxygen; Selective Binding; Selective Microbicidal Action; Normal Flora

\section{Introduction}

In 1892 Döderlein suggested that fermentative lactic acid producing vaginal bacteria protected the host from pathogenic microbes [1]. The role of Döderlein's bacillus, i.e., Lactobacillus acidiphilus, in healthy vaginal flora, was extended to include the normal intestinal bacterial flora of infants by Moro in 1900 [2]. At about the same time Tissier described the normal flora of breast-fed infants, establishing the importance of Bifidobacteria (aka, Tissier's bacillus) [3]. In 1908 the health benefits of the lactic acid bacteria that constitute healthy human flora were popularized by Metchnikoff's book, Prolongation of Life [4].

The lactic acid bacteria (LAB) are Gram-positive, nonspore forming microbes incapable of cytochrome synthesis and lacking the heme electron transport mechanisms required for efficient respiration. As such, LAB metabolism is fermentative. The LAB are acid-tolerant, aerotolerant and lack heme catalase activity [5]. The absence of cytochromes restricts $\mathrm{LAB}$ redox metabolism to flavoenzymes. The resultant fermentative metabolism produces acids, and in many cases, hydrogen peroxide $\left(\mathrm{H}_{2} \mathrm{O}_{2}\right)$ [6]. LAB fermentative metabolism is essential to food preservation. In their role as the dominant microbes of the normal flora, LAB serve the innate host defense 
against pathogenic microbes.

Many LAB produce $\mathrm{H}_{2} \mathrm{O}_{2}$ in the presence of oxygen $[7,8]$. The viridans streptococci that comprise the normal mouth flora [9] produce sufficient $\mathrm{H}_{2} \mathrm{O}_{2}$ to cause the characteristic green, i.e., viridans, hemolysis seen on blood agar [10]. Streptococcus sanguinis and Streptococcus mitis are reported to produce $\mathrm{H}_{2} \mathrm{O}_{2}$ in the range of about 50 nanomoles $(\mathrm{nmol}) / \mathrm{min} / \mathrm{mg}$ of dry weight [11]. The rates of $\mathrm{H}_{2} \mathrm{O}_{2}$ production by Streptococcus oralis and $S$. sanguinis are described to be several nanograms $/ \mathrm{min}$ $/ 10^{6} \mathrm{CFU}[12]$.

\section{Phagocyte Leukocyte Microbicidal Action}

Neutrophil leukocytes and monocytes provide the innate phagocyte defense against pathogenic infection and are the microbicidal effector cells of the acute inflammatory response. Large quantities of neutrophils and monocytes are produced by the myelopoietic bone marrow and released into the circulating blood daily. Cytokines and chemotactic molecules direct phagocyte migration from the circulating blood to sites of infection where contact with opsonified microbes results in phagocytosis and formation of a phagosome. Fusion of the phagosome with lysosomal azurophilic granules containing cationic enzymes produces the phagolysosome. Both neutrophils and monocytes contain relatively large quantities of a cationic haloperoxidase, i.e., myeloperoxidase (MPO) [13], capable of oxidizing chloride $\left(\mathrm{Cl}^{-}\right)$to hypochlorite $\left(\mathrm{OCl}^{-}\right)$in an acid milieu containing $\mathrm{H}_{2} \mathrm{O}_{2}$ [14].

As depicted in the schematic of Figure 1, phagocytosis is linked to activation of NADPH oxidase. The activated oxidase catalyzes the NADPH-dependent reduction of molecular oxygen $\left(\mathrm{O}_{2}\right)$ liberating the $\mathrm{NADP}^{+}$required for increased hexose monophosphate shunt (aka, pentose pathway) dehydrogenase activity. This increased glucose metabolism is proportional to increased non-mitochondrial oxygen consumption. These metabolic activities are

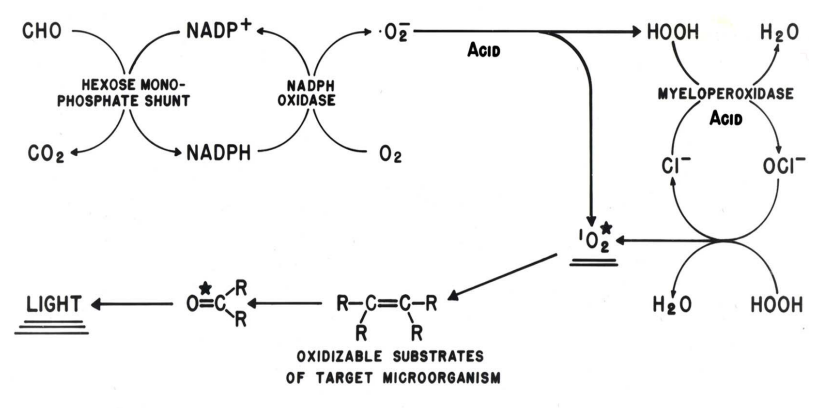

MICROBICIDAL METABOLISM OF THE PMN LEUKOCYTE

Figure 1. Schematic depiction of neutrophil production of the $\mathrm{H}_{2} \mathrm{O}_{2}$ that drives MPO oxidation of $\mathrm{Cl}^{-}$to $\mathrm{OCl}^{-}$, followed by reaction of the $\mathrm{OCl}^{-}$with an additional $\mathrm{H}_{2} \mathrm{O}_{2}$ to produce ${ }^{1} \mathrm{O}_{2}^{*}$. The resulting microbicidal dioxygenation reactions yield excited carbonyl products that relax by photon emission, i.e., chemiluminescence [15]. necessary for phagolysosomal acidification and $\mathrm{H}_{2} \mathrm{O}_{2}$ production, and provide an optimal milieu for $\mathrm{H}_{2} \mathrm{O}_{2}$ dependent MPO oxidization of $\mathrm{Cl}^{-}$to $\mathrm{OCl}^{-}$[15-18]. The reaction of $\mathrm{OCl}^{-}$with a second $\mathrm{H}_{2} \mathrm{O}_{2}$ yields electronically excited singlet molecular oxygen $\left({ }^{1} \mathrm{O}_{2}^{*}\right)$, a highly reactive but metastable electrophilic oxygenating agent with a microsecond lifetime. Both $\mathrm{OCl}^{-}$and $\left({ }^{1} \mathrm{O}_{2}^{*}\right)^{*}$ are potent microbicidal agents.

\subsection{Phagocyte Production and Myeloperoxidase}

Each day the bone marrow of a healthy human adult releases about a hundred billion neutrophils and monocytes into the circulating blood [19]. Approximately 5\% of the dry weight of each neutrophil is MPO [20], a $145 \mathrm{kDa}$ dimeric alpha-heme haloperoxidase carried in the neutrophil's azurophilic granules [13]. The average cell volume of a neutrophil is about 450 femtoliter (fL); its specific gravity is 1.1 , and its cell water content is about $84 \%$ (16\% dry weight). As such, each neutrophil contains about 4 femtograms (fg) MPO. Thus, the total MPO released per day is about $0.4 \mathrm{mg}$. Nanomolar concentrations $(0.1-1.0 \mu \mathrm{g} / \mathrm{mL})$ of MPO are highly microbicidal when presented with physiologically available chloride and sub-millimolar concentrations of $\mathrm{H}_{2} \mathrm{O}_{2}$ [21].

\subsection{Tissue Neutrophils and MPO Availability}

The circulating lifetime of neutrophils in the blood is less that twelve hours, and is followed by a less well characterized tissue phase that can last for a few days [19]. Although neutrophilia, i.e., influx of neutrophils, is a characteristic feature of acute inflammation, small numbers of neutrophils are known to routinely migrate into the alimentary tract spaces, bladder and body cavities in the absence of inflammation. Continuous migration of neutrophils into the mouth [22] and vagina [23] has been well documented. Relatively large numbers of neutronphils $\left(10^{5}\right)$ can be lavaged from the mouths of healthy humans. The quantity of neutrophils present in fluid lavaged from the mouth is proportional to the subject's circulating blood neutrophil counts [22]. Inflammation and G-CSF treatment increase neutrophil production as well as the quantity of MPO per neutrophil $[24,25]$.

Migrating tissue phase neutrophils transport sufficient MPO to body flora spaces to have an effect on the microbial flora. The presence of MPO might be expected to exert microbicidal action against the resident $\mathrm{H}_{2} \mathrm{O}_{2}$-producing LAB [26,27], but the opposite is observed.

\section{MPO Selectivity Binds and Kills Microbes}

Direct MPO binding to bacteria can be visually demonstrated by contacting bacteria in suspension with MPO, and then pelleting the bacteria by centrifugation. The degree of bacterial pellet staining is proportional to the 
MPO bound [21]. MPO was found to bind to all of the Gram-negative, and most of the Gram-positive bacteria tested, with the exception of viridans streptococcus, i.e., $S$. sanguinis. The degree of MPO binding was quantified by reduced-minus-oxidized difference spectral analysis and by chemiluminescence-based Scatchard analysis. Both methods confirmed and expanded the visual observation of selective MPO binding. With the exception of the fermentative LAB, all bacteria tested showed high degrees of MPO binding [28-30].

Furthermore, MPO binding correlates with MPO killing. Bacteria showing strong MPO binding were rapidly and effectively killed when MPO was present in nanomolar quantities with about 100 micromolar $(\mu \mathrm{M}) \mathrm{H}_{2} \mathrm{O}_{2}$ (i.e., a greater than thousandfold dilution of 3\% pharmacy $\mathrm{H}_{2} \mathrm{O}_{2}$ ). Streptococci and lactobacilli show relatively weak MPO-binding, and as such, these LAB are relatively protected from MPO microbicidal action.

\subsection{Hypochlorite and Microbicidal Action}

In the acidic milieu of the neutrophil's phagolysosome, or in acidic body spaces populated by LAB flora, MPO catalyzes the oxidation of chloride $\left(\mathrm{Cl}^{-}\right)$to hypochlorous acid (HOCl). Hypochlorite, the conjugate base of hypochlorous acid, is the active ingredient in household bleach, and has been employed as a disinfectant and deodorizing agent since Claude Louis Berthollet introduced it as Eau de Javel in 1789 [31-33]. Hypochlorous acid is a weak acid with a pKa of 7.5 , and as such, the acid predominates in phagolysosomal and fermentation milieux.

The chloronium $\left(\mathrm{Cl}^{+}\right)$character of $\mathrm{HOCl}$ allows it to participate in a variety of reactions resulting in dehydrogenations and chloramine formation. The bactericidal action of hypochlorite is broad and complete at a concentration of $6 \mu \mathrm{M}$. However, a thousandfold higher hypochlorite concentration, i.e., $6 \mathrm{mM}$, is required for the same level of microbicidal action when human erythrocytes are added at a ratio of about five erythrocytes per bacterium [21]. Although hypochlorite shows potent microbicidal action, it lacks specificity, confirming Alexander Fleming's comment that "leukocytes are more sensitive to the action of chemical antiseptics than are the bacteria, and, in view of this, it is unlikely that any of these antiseptics have the power of penetrating into the tissues and destroying the bacteria without first killing the tissues themselves" [34].

\subsection{Reaction Radius of Singlet Oxygen}

The critical importance of microbe-specific MPO binding is best understood relative to the reactive lifetime of ${ }^{1} \mathrm{O}_{2}^{*}$ and its restricted radius of reactivity $[35,36]$. Like chlorine gas $\left(\mathrm{Cl}_{2}\right),{ }^{1} \mathrm{O}_{2}^{*}$ has singlet spin multiplicity, is a potent electrophilic reactant, and participates in highly exergonic reactions [18,37]. Unlike $\mathrm{Cl}_{2},{ }^{1} \mathrm{O}_{2}^{*}$ is a metastable electronically excited state with a relatively short lifetime. Singlet spin multiplicity is critically important for reactivity. Understanding the role of multiplicity in ${ }^{1} \mathrm{O}_{2}^{*}$ reactivity is best approached by considering the Wigner spin conservation rules [38,39]. In essence, the neutrophil leukocyte changes the spin quantum number of oxygen, thus removing the barrier to spin-allowed reaction with singlet multiplicity biological molecules. The wet combustive oxygenations that follow produce electronically excited oxygenation products. As shown in Figure 1, light emission or chemiluminescence (CL) is an energy product of $\pi^{*} \rightarrow \mathrm{n}$ electron relaxation of the excited carbonyl functions generated.

The short lifetime of ${ }^{1} \mathrm{O}_{2}^{*}$ restricts reactivity to within a space of less than a micron from its point of generation $[28,40,41]$. MPO microbicidal effectiveness is limited by its proximity to the target microbe. For successful microbicidal action, primary production of $\mathrm{HOCl}$, and especially, secondary production of ${ }^{1} \mathrm{O}_{2}^{*}$, must occur sufficiently close to the target microbe for adequate oxygenation activity. The concentration of $\mathrm{HOCl}$ decreases with the distance from the MPO production site. Once $\mathrm{HOCl}$ reacts with a second $\mathrm{H}_{2} \mathrm{O}_{2}$ molecule to generate ${ }^{1} \mathrm{O}_{2}^{*}$, the reactive radius is restricted to within about $0.2 \mu \mathrm{m}$. Chloramines produced by direct reaction of $\mathrm{HOCl}$ with amine components of the microbe, also react with additional $\mathrm{H}_{2} \mathrm{O}_{2}$ to produce ${ }^{1} \mathrm{O}_{2}^{*}$, and such reactions are facilitated by an acidic milieu.

The results of Figure 2 illustrate the relationship of selective binding to selective killing. In this experiment, suspensions of Escherichia coli $\left(\sim 10^{6}\right)$ and S. sanguinis $\left(\sim 10^{7}\right)$ plus human erythrocytes $\left(\sim 10^{7}\right)$ were added together to yield a final ratio of about one E. coli to ten $S$. sanguinis and to five erythrocytes. The top plate shows the results in the absence of MPO. Note the presence of large colonies of E. coli and the absence of small S. sanguinis colonies. The middle plate shows the consequence of including $1.9 \mathrm{nM}$ MPO. This small concentration of MPO significantly decreased the colonies of E. coli and also allowed the emergence of small colonies of $S$. sanguinis. The bottom plate shows the effects of $5.6 \mathrm{nM}$ MPO. Only a single colony of E. coli developed, however, several hundred small colonies of $S$. sanguinis are now clearly visible.

In this experiment $S$. sanguinis metabolism is the only source of $\mathrm{H}_{2} \mathrm{O}_{2}$. E. coli are catalase positive and relatively well protected from low concentrations of $\mathrm{H}_{2} \mathrm{O}_{2}$. Erythrocytes show no significant MPO binding and contain abundant catalase. Introducing $10^{7}$ erythrocytes with their several magnitudes greater mass than $E$. coli also provides competitive substrate for reaction with available oxidants. The absence of measurable hemolysis con 


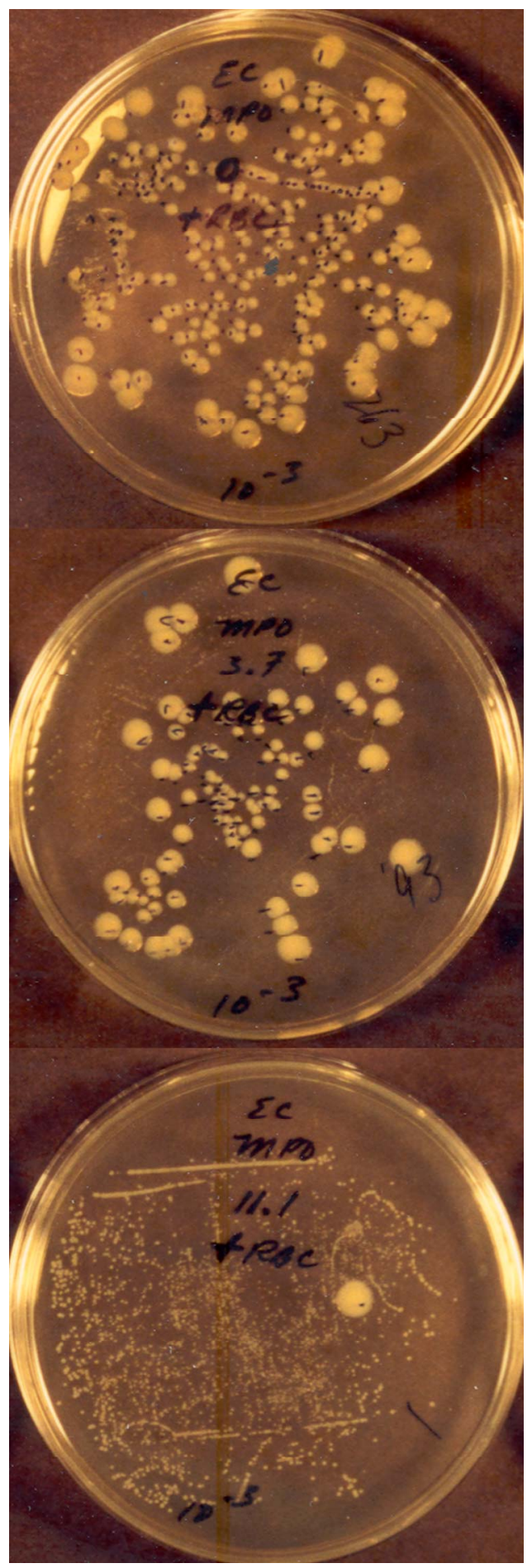

Figure 2. Effects of MPO on a co-suspension of live $E$. coli and $S$. sanguinis (about one $E$. coli per ten $S$. sanguinis) after thirty minutes exposure at $23^{\circ} \mathrm{C}$. The $10^{-3} \mathrm{CFU}$ dilution Petri plates are shown. Human erythrocytes were present at a ratio of about five erythrocytes per $E$. coli. $\mathrm{No}_{2} \mathrm{H}_{2}$ was added. The suspension of the top plate contained no MPO, the suspension of the middle plate contained $1.9 \mathrm{nM}$ MPO, and the suspension of the bottom plate contained 5.6 $\mathrm{nM}$ MPO. The plates were allowed to incubate for more than a day to allow growth of the smaller $S$. sanguinis colonies [21]. firmed the absence of erythrocyte damage during the course of the experiment [21].

LAB-MPO microbicidal action in the presence of erythrocytes demonstrates the highly selective nature of MPO-mediated oxidative attack. Only the MPO-binding E. coli were killed. The absence of significant MPObinding to $S$. sanguinis and erythrocytes, and the proximity requirement imposed by the lifetime of ${ }^{1} \mathrm{O}_{2}^{*}$ allow LAB-MPO synergistic microbicidal action against $E$. coli. In the presence of relatively low $\mathrm{H}_{2} \mathrm{O}_{2}$ concentrations and low MPO concentrations, selectivity of MPO binding results in selectivity of killing.

\section{LAB Fermentative Metabolism and MPO}

LAB are incapable of cytochrome synthesis, and conesquently, metabolism is fermentative. Nonetheless, these LAB play dominant roles in the flora of the mouth, vagina and lower gastrointestinal tract. In contradistinction to other Gram-positive and to all Gram-negative bacteria, LAB show very low MPO binding. LAB fermentative metabolism provides the acidic milieu and sufficient $\mathrm{H}_{2} \mathrm{O}_{2}$ for MPO microbicidal action, as demonstrated by the results shown in Figure 2, and illustrated in the schematic of Figure 3.

LAB show poor MPO binding. Thus, the proximity requirement necessary for effective MPO microbicidal action spares LAB. At low MPO concentrations LAB are protected from their metabolic product $\mathrm{H}_{2} \mathrm{O}_{2}$. Instead, LAB-MPO synergistic microbicidal action is focused on competing MPO-binding microbes. The presence MPO in milieux containing LAB favors the killing of microbes showing significant MPO binding. As such, LAB-MPO synergy provides a mechanism for establishing and maintaining $\mathrm{LAB}$ as the dominant microbes of the normal flora of man.

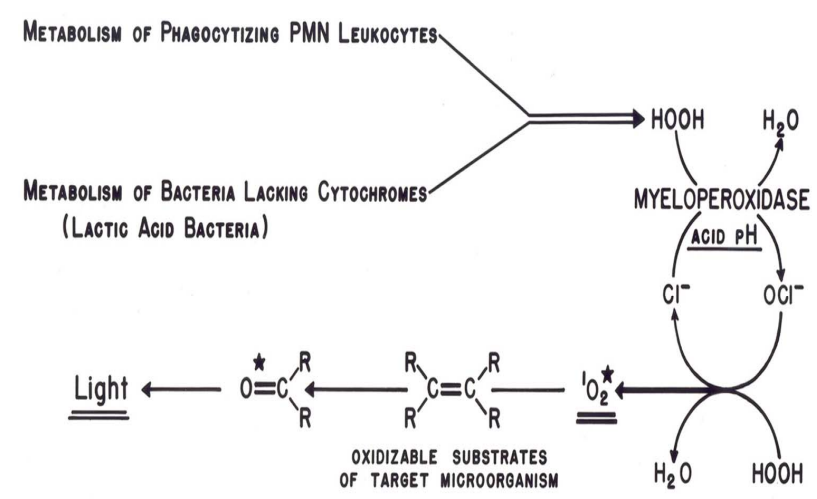

Mechanisim of Myeloperoxioase Microbicioal Action

Figure 3. Similar roles of neutrophil metabolism and LAB metabolism in driving MPO combustive microbicidal action with chemiluminescence [17]. 


\section{Acknowledgements}

The support of ExOxEmis, Inc. is gratefully acknowledged.

\section{REFERENCES}

[1] "Das Scheidensekret und seine Bedeutung für das Puerperalfieber," Centralblatt für Bacteriologie, Vol. 11, 1892, pp. 699-700.

[2] E. Moro, "Über den Bacillus acidophilus n. spec. Ein Beitrag zur Kenntnis der normalen Darmbacterien des Säuglings," Jahrbuch für Kinderheilkunde, Vol. 52, 1900, pp. 38-55.

[3] H. Tissier, "Recherchers sur la Flora Intestinale Normale et Pathologique du Nourisson," Thesis, University of Paris, Paris, 1900.

[4] E. Metchnikoff, "Prolongation of Life," Putnam, New York, 1908.

[5] W. H. Holzapfel, P. Haberer, R. Geisen, J. Björkroth and U. Schillinger, "Taxonomy and Important Features of Probiotic Microorganisms in Food and Nutrition," The American Journal of Clinical Nutrition, Vol. 73, 2001, pp. 365S-373S.

[6] J. W. McLeod and J. Gordon, "Production of Hydrogen Peroxide by Bacteria," Biochemical Journal, Vol. 16, 1922, pp. 499-504.

[7] R. Whittenbury, "Hydrogen Peroxide Formation and Catalase Activity in Lactic Acid Bacteria," Journal of General Microbiology, Vol. 35, No. 1, 1964, pp. 13-26. http://dx.doi.org/10.1099/00221287-35-1-13

[8] C. Marty-Teysset, F. de la Torre and J. Garel, "Increased Production of Hydrogen Peroxide by Lactobacillus delbrueckii subsp. bulgaricus upon Aeration: Involvement of an NADH Oxidase in Oxidative Stress," Applied and Environmental Microbiology, Vol. 66, 2000, pp. 262-267. http://dx.doi.org/10.1128/AEM.66.1.262-267.2000

[9] D. A. Johnston and G. P. Bodey, "Semiquantitative Oropharyngeal Culture Technique," Journal of Applied Microbiology, Vol. 20, 1970, pp. 218-223.

[10] J. P. Barnard and M. W. Stinson, "The Alpha Hemolysin of Streptococcus gordonii is Hydrogen Peroxide," Infection and Immunity, Vol. 64, 1996, pp. 3853-3857.

[11] J. Carlsson, Y. Iwami and T. Yamada, "Hydrogen Peroxide Excretion by Oral Streptococci and Effect of Lactoperoxidase-Thiocyanate-Hydrogen Peroxide," Infection and Immunity, Vol. 40, 1983, pp. 70-80.

[12] A. Garcia-Mendoza, J. Liebana, A. M. Castillo, A. de la Higuera and G. Piedrola, "Evaluation of the Capacity of Oral Streptococci to Produce Hydrogen Peroxide," Journal of Medical Microbiology, Vol. 39, No. 6, 1993, pp. 434-439. http://dx.doi.org/10.1099/00222615-39-6-434

[13] K. Agner, "Crystalline Myeloperoxidase," Acta Chemica Scandinavica, Vol. 12, 1958, pp. 89-94. http://dx.doi.org/10.3891/acta.chem.scand.12-0089

[14] R. C. Allen, "Studies on the Generation of Electronic Excitation States in Human Polymorphonuclear Leukocytes and their Participation in Microbicidal Action,"
Ph.D. Dissertation, Tulane University, New Orleans, 1973.

[15] R. C. Allen, S. J. Yevich, R. W. Orth and R. H. Steele, "The Superoxide Anion and Singlet Molecular Oxygen: Their Role in the Microbicidal Activity of the Polymorphonuclear Leukocyte," Biochemical and Biophysical Research Communications, Vol. 60, No. 3, 1974, pp. 909917. http://dx.doi.org/10.1016/0006-291X(74)90401-X

[16] R. C. Allen, "Halide Dependence of the Myeloperoxidase-Mediated Antimicrobial System of the Polymorphonuclear Leukocyte in the Phenomenon of Electronic Excitation," Biochemical and Biophysical Research Communications, Vol. 63, No. 3, 1975, pp. 675-683. http://dx.doi.org/10.1016/S0006-291X(75)80437-2

[17] R. C. Allen, "The Role of $\mathrm{pH}$ in the Chemiluminescent Response of the Myeloperoxidase-Halide-HOOH Antimicrobial System," Biochemical and Biophysical Research Communications, Vol. 63, No. 3, 1975, pp. 684-691. http://dx.doi.org/10.1016/S0006-291X(75)80438-4

[18] R. C. Allen, "Reduced, Radical, and Electronically Excited Oxygen in Leukocyte Microbicidal Metabolism," In: J. T. Dingle and P. J. Jacques, Eds., Lysosomes in Biology and Pathology, Vol. 6; In: A. Neuberger and E. L. Tatum, Eds., Frontiers in Biology, Vol. 48, North Holland, Amsterdam, 1979, pp. 197-233.

[19] D. F. Bainton, "Developmental Biology of Neutrophils and Eosinophils," In: J. I. Gallin and R. S. Snyderman, Eds., Inflammation, Basic Principles and Clinical Correlates, 3rd Edition, Lippincott Williams \& Wilkins, Philadelphia, 1999, pp. 13-34.

[20] J. Schultz and K. Kaminker, "Myeloperoxidase of the Leukocyte of Normal Human Blood. I. Content and Localization," Archives of Biochemistry and Biophysics, Vol. 96, No. 3, 1962, pp. 465-467. http://dx.doi.org/10.1016/0003-9861(62)90321-1

[21] R. C. Allen and J. T. Stephens Jr., "Myeloperoxidase Selectively Binds and Selectively Kills Microbes," Infection and Immunity, Vol. 79, No. 1, 2011, pp. 474-485. http://dx.doi.org/10.1128/IAI.00910-09

[22] D. G. Wright, A. I. Meierovics and J. M. Foxley, “Assessing the Delivery of Neutrophils to Tissues in Neutropenia," Blood, Vol. 67, 1986, pp. 1023-1030.

[23] S. Cauci, S. Guaschino, D. de Aloysio, S. Driussi, D. De Santo, P. Penacchioni and F. Quadrifoglio. "Interrelationships of Interleukin-8 with Interleukin-1 $\beta$ and Neutrophils in Vaginal Fluid of Healthy and Bacterial Vaginosis Positive Women," Molecular Human Reproduction, Vol. 9, No. 1, 2003, pp. 53-58. http://dx.doi.org/10.1093/molehr/gag003

[24] R. C. Allen, P. R. Stevens, T. H. Price, G. S. Chatta and D. C. Dale. "In Vivo Effects of Recombinant Human Granulocyte Colony-Stimulating Factor on Neutrophil Oxidative Functions in Normal Human Volunteers," The Journal of Infectious Diseases, Vol. 175, No. 5, 1997, pp. 1184-1192. http://dx.doi.org/10.1086/595866

[25] R. C. Allen, D. C. Dale and F. B. Taylor Jr., "Blood Phagocyte Luminescence: Gauging Systemic Immune Activation," Methods in Enzymology, Vol. 305, 2000, pp. 591-629.

http://dx.doi.org/10.1016/S0076-6879(00)05515-4 
[26] S. J. Klebanoff, "Myeloperoxidase-Halide-Hydrogen Peroxide Antibacterial System," Journal of Bacteriology, Vol. 95, 1968, pp. 2131-2138.

[27] R. C. Allen, E. L. Mills, T. R. McNitt and P. G. Quie, "Role of Myeloperoxidase and Bacterial Metabolism in Chemiluminescence of Granulocytes from Patients with Chronic Granulomatous Disease," The Journal of Infectious Diseases, Vol. 144, No. 4, 1981, pp. 344-348. http://dx.doi.org/10.1093/infdis/144.4.344

[28] R. C. Allen, "Method for Selectively Inhibiting the Growth of Microbes Using a Haloperoxidase-HalidePeroxide System," US Patent No. 5,888,505, 1999.

[29] R. C. Allen and J. T. Stephens Jr., "Reduced-Oxidized Difference Spectral Analysis and ChemiluminescenceBased Scatchard Analysis Demonstrate Selective Binding of Myeloperoxidase to Microbes," Luminescence, Vol. 26, No. 3, 2010, pp. 208-213. http://dx.doi.org/10.1002/bio.1210

[30] R. C. Allen and J. T. Stephens Jr., "Phagocyte and Extra-Phagocyte Myeloperoxidase-Mediated Microbicidal Action," In: A. Mendez-Vilas, Ed., Science Against Microbial Pathogens: Communicating Current Research and Technical Advances, Formatex Res. Ctr., Badajoz, 2011, pp. 613-621.

[31] H. D. Dakin, "The Antiseptic action of Hypochlorites," British Medical Journal, Vol. 2, 1915, pp. 809-810. http://dx.doi.org/10.1136/bmj.2.2866.809

[32] C. T. Butterfield, E. Wattie, S. Megregian and C. W. Chambers, "Influence of $\mathrm{pH}$ and Temperature on the Survival of Coliforms and Enteric Pathogens When Exposed to Chlorine," Public Health Reports, Vol. 58, No. 51, 1943, pp. 1837-1866. http://dx.doi.org/10.2307/4584715

[33] L. Friberg and E. Hammarström, "The Action of Free Available Chlorine on Bacteria and Bacterial Viruses," Acta Pathologica Microbiologica Scandinavica, Vol. 38, No. 2, 1956, pp. 127-134. http://dx.doi.org/10.1111/j.1699-0463.1956.tb00986.x

[34] A. Fleming, "The Action of Chemical and Physiological Antiseptics in a Septic Wound," British Journal of Surgery, Vol. 7, No. 25, 1919, pp. 99-129. http://dx.doi.org/10.1002/bjs.1800072508

[35] M. Kasha and A. U. Khan, "The Physics, Chemistry, and Biology of Singlet Molecular Oxygen," Annals of the New York Academy of Sciences, Vol. 171, 1970, pp. 5-23. http://dx.doi.org/10.1111/j.1749-6632.1970.tb39294.x

[36] A. M. Held, D. J. Halko and J. K. Hurst, "Mechanism of Chlorine Oxidation by Hydrogen Peroxide," Journal of the American Chemical Society, Vol. 100, No. 18, 1978, pp. 5732-5740. http://dx.doi.org/10.1021/ja00486a025

[37] R. C. Allen, "Role of Oxygen in Phagocyte Microbicidal Action," Environmental Health Perspectives, Vol. 102, No. S10, 1994, pp. 201-208.

[38] R. C. Allen, "Oxygen-Dependent Microbe Killing by Phagocytic Leukocytes: Spin Conservation and Reaction Rate," In: W. Ando and Y. Moro-oka, Eds., Studies in Organic Chemistry, Vol. 33, The Role of Oxygen in Chemistry and Biochemistry, Elsevier Press, Amsterdam 1988, pp. 425-434.

[39] R. C. Allen, "Molecular Oxygen $\left(\mathrm{O}_{2}\right)$ : Reactivity and Luminescence," In: L. J. Kricka and P. E. Stanley, Eds., Bioluminescence and Chemiluminescence 2002, World Scientific, Singapore, 2002, pp. 223-232.

[40] R. W. Redmond and I. E. Kochevar, "Spatially Resolved Cellular Responses to Singlet Oxygen," Photochemistry and Photobiology, Vol. 82, No. 5, 2006, pp. 1172-1186. http://dx.doi.org/10.1562/2006-04-14-IR-874

[41] E. Skovsen, J. W. Snyder, J. D. C. Lambert and P. R. Ogilby, "Lifetime and Diffusion of Singlet Oxygen in a Cell," The Journal of Physical Chemistry B, Vol. 109, No. 18, 2005, 8570-8573. http://dx.doi.org/10.1021/jp051163i 